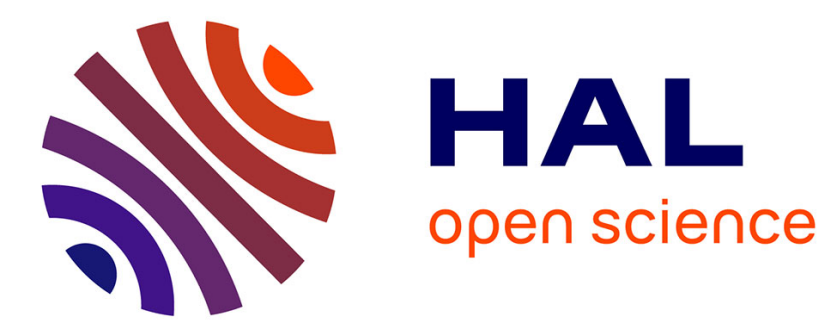

\title{
Bird terrestrial locomotion as revealed by 3D kinematics
}

Anick Abourachid, Rémi Hackert, Marc Herbin, Paul A Libourel, François

Lambert, Henri Gioanni, Pauline Provini, Pierre Blazevic, Vincent Hugel

\section{To cite this version:}

Anick Abourachid, Rémi Hackert, Marc Herbin, Paul A Libourel, François Lambert, et al.. Bird terrestrial locomotion as revealed by 3D kinematics. Zoology, 2011, 114 (6), pp.360-368. 10.1016/j.zool.2011.07.002 . hal-02341355

\section{HAL Id: hal-02341355 \\ https://hal.science/hal-02341355}

Submitted on 11 Nov 2019

HAL is a multi-disciplinary open access archive for the deposit and dissemination of scientific research documents, whether they are published or not. The documents may come from teaching and research institutions in France or abroad, or from public or private research centers.
L'archive ouverte pluridisciplinaire HAL, est destinée au dépôt et à la diffusion de documents scientifiques de niveau recherche, publiés ou non, émanant des établissements d'enseignement et de recherche français ou étrangers, des laboratoires publics ou privés. 


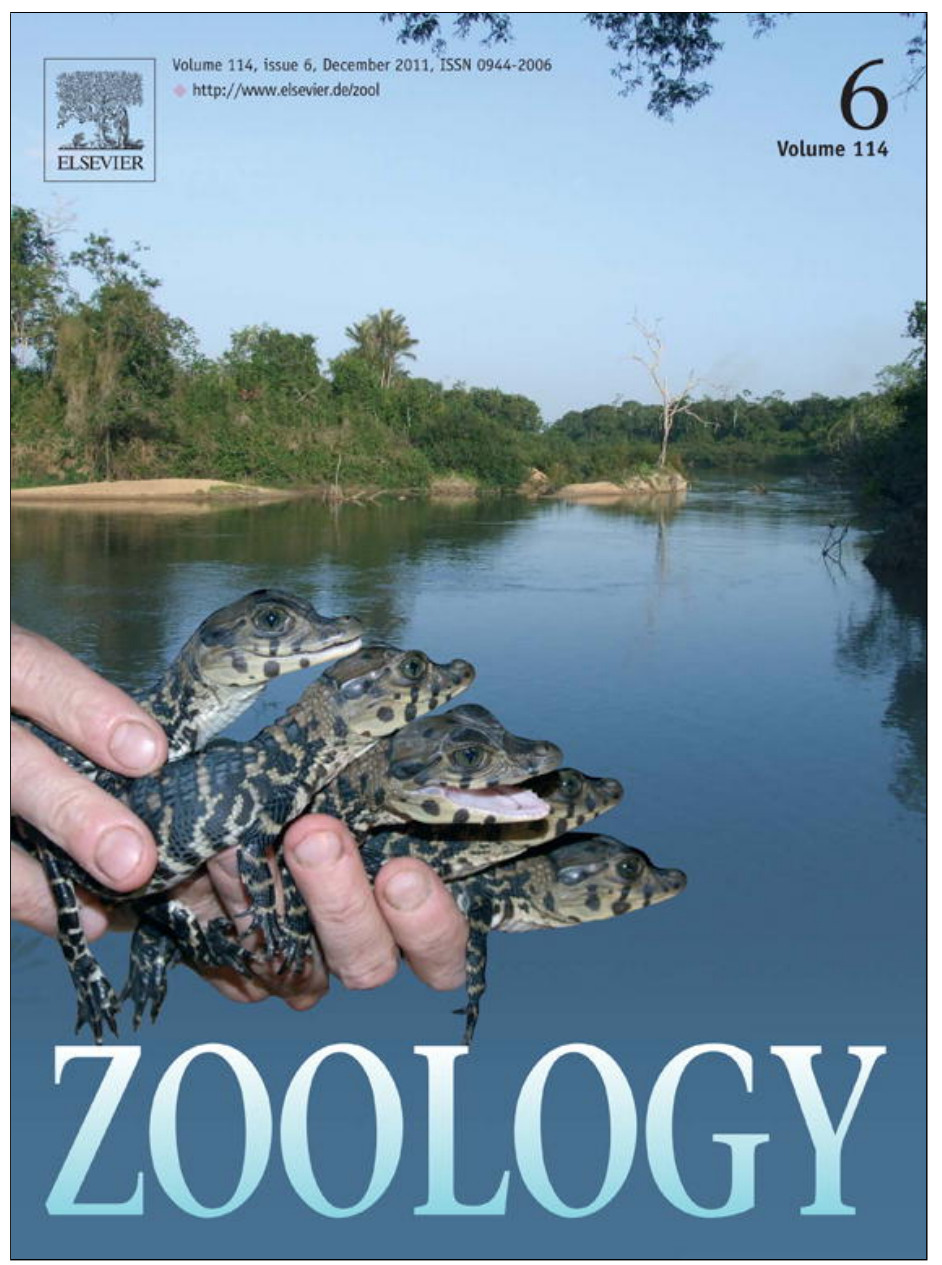

This article appeared in a journal published by Elsevier. The attached copy is furnished to the author for internal non-commercial research and education use, including for instruction at the authors institution and sharing with colleagues.

Other uses, including reproduction and distribution, or selling or licensing copies, or posting to personal, institutional or third party websites are prohibited.

In most cases authors are permitted to post their version of the article (e.g. in Word or Tex form) to their personal website or institutional repository. Authors requiring further information regarding Elsevier's archiving and manuscript policies are encouraged to visit:

http://www.elsevier.com/copyright 


\title{
Bird terrestrial locomotion as revealed by 3D kinematics
}

\author{
Anick Abourachid a,*, Remi Hackert ${ }^{a}$, Marc Herbin a , Paul A. Libourel ${ }^{\mathrm{a}}$, François Lambert ${ }^{\mathrm{a}, \mathrm{b}}$, \\ Henri Gioanni ${ }^{\mathrm{b}}$, Pauline Provini ${ }^{\mathrm{a}}$, Pierre Blazevic ${ }^{\mathrm{c}}$, Vincent Hugel ${ }^{\mathrm{c}}$ \\ a Département EGB, Muséum National d'Histoire Naturelle, Pavillon d'Anatomie Comparée, 57 rue Cuvier, F-75231 Paris Cedex 05, France \\ ${ }^{\mathrm{b}}$ Laboratoire de Neurobiologie des Réseaux Sensorimoteurs, Université Paris 5, 45 rue des Saints-Pères, F-75270 Paris Cedex 06, France \\ ' Laboratoire d'Ingénierie des Systèmes de Versailles, Université de Versailles Saint Quentin en Yvelines, 10-12 avenue de l'Europe, F-78140 Velizy, France
}

\section{A R T I C L E I N F O}

\section{Article history:}

Received 11 December 2010

Received in revised form 6 June 2011

Accepted 4 July 2011

\section{Keywords:}

Coturnix coturnix

Bird anatomy

Bird locomotion

Head bobbing

3D kinematics

\begin{abstract}
A B S T R A C T
Most birds use at least two modes of locomotion: flying and walking (terrestrial locomotion). Whereas the wings and tail are used for flying, the legs are mainly used for walking. The role of other body segments remains, however, poorly understood. In this study, we examine the kinematics of the head, the trunk, and the legs during terrestrial locomotion in the quail (Coturnix coturnix). Despite the trunk representing about $70 \%$ of the total body mass, its function in locomotion has received little scientific interest to date. This prompted us to focus on its role in terrestrial locomotion. We used high-speed video fluoroscopic recordings of quails walking at voluntary speeds on a trackway. Dorso-ventral and lateral views of the motion of the skeletal elements were recorded successively and reconstructed in three dimensions using a novel method based on the temporal synchronisation of both views. An analysis of the trajectories of the body parts and their coordination showed that the trunk plays an important role during walking. Moreover, two sub-systems participate in the gait kinematics: (i) the integrated 3D motion of the trunk and thighs allows for the adjustment of the path of the centre of mass; (ii) the motion of distal limbs transforms the alternating forward motion of the feet into a continuous forward motion at the knee and thus assures propulsion. Finally, head bobbing appears qualitatively synchronised to the movements of the trunk. An important role for the thigh muscles in generating the 3D motion of the trunk is suggested by an analysis of the pelvic anatomy.
\end{abstract}

(c) 2011 Elsevier GmbH. All rights reserved.

\section{Introduction}

In most birds, at least two modes of locomotion coexist: flying and terrestrial locomotion, even though many of them also swim. Most birds escape by flying and forage by walking or hopping. Although the body of a bird appears to be optimally shaped for flying, it must also function during walking, landing and take-off.

The body of a bird can be considered a complex and integrated system consisting of several main parts: a mobile head and a flexible neck; a large rigid trunk with a short bony tail; two wings; and two legs. Despite a great variety in the ecology and lifestyle of birds, this pattern is highly conserved. Whereas the wings and tail are used during flight but not during walking, the legs are used mainly during walking (Gatesy and Dial, 1996). In some species, movements of the head during walking are also obvious (Necker, 2007).

Previously, the hindlimb kinematics of birds has been examined to better understand the biomechanics and motor control during terrestrial locomotion. These studies suggested that the patterns of

\footnotetext{
* Corresponding author. Tel.: +33140793308.

E-mail address: abourach@mnhn.fr (A. Abourachid).
}

walking, running, and even hopping are conserved among birds, with modulations of the angular displacements being linked to changes in locomotor speed (Cracraft, 1971; Gatesy and Biewener, 1991; Reilly, 2000; Verstappen and Aerts, 2000). More obvious movements such as head-bobbing, known to be a gaze stabilisation reflex linked to behaviour (Frost, 1978; Troje and Frost, 2000; Fujita, 2002), have been studied in connection with the biomechanics of walking (Dagg, 1977; Clark and Alexander, 1975; Fujita, 2002, 2003). As during walking the trunk barely moves (Verstappen and Aerts, 2000; Gatesy, 1999a; Rubenson et al., 2007), its function has not been considered previously.

Studies on locomotion in birds have mostly focused on the mechanisms used to generate propulsion. The movements of the limbs and the centre of mass in the sagittal and vertical planes have been analysed most often, as they have the largest amplitude. Although medio-lateral limb movements are known to participate in adjusting the kinematics of locomotion (Gatesy, 1999a; Rubenson et al., 2007), the medio-lateral movements of the trunk are much smaller and typically ignored. Despite the large fraction of the total body mass represented by the trunk (including the wings; roughly $70 \%$ of the entire body mass in quail), its implications on the three-dimensional (3D) trunk kinematics during walking have 
received little attention. However, given its large mass, even though the magnitude of the trunk motion is small, it will affect the dynamics of the entire body during locomotion.

To examine the roles of the different body parts during terrestrial locomotion, we reconstructed whole-body kinematics based on high-speed videofluoroscopic recordings. In the present study, we describe the 3D kinematics of the different body parts during walking, with a special focus on the trunk, and assess the synchronisation of body parts in three dimensions.

\section{Materials and methods}

\subsection{Animals}

We used the quail (Coturnix coturnix) as a model for a generalized walking bird because it tends to walk more than it flies. It is, however, not a walking specialist as the wild common quail is migratory and thus also a good flier (McGowan, 1994).

As feathers conceal the entire body except the head and the distal part of the hindlimbs, we used videofluoroscopic methods to study the motion of the skeleton. As the head-bobbing reflex is triggered by visual inputs on the retina (Troje and Frost, 2000), this behaviour does not occur when birds, like the quail, walk on a treadmill. Therefore, we used a mobile videofluoroscopic setup that followed the animal as it moved along a trackway. Birds were filmed first in lateral, then in dorso-ventral view.

We used five quails $(151 \pm 5 \mathrm{~g}$, hip height at mid stance: $9.9 \pm 0.4 \mathrm{~cm}$ ) bred specifically to display little stress when disturbed. The movement of anatomical landmarks was quantified using radio-opaque markers, visible in both lateral and dorsoventral views. Anatomical points were identified by palpation and markers were glued onto the birds' skin where the skin adheres to the bone. As the knee moves relative to the skin during walking, the knee markers were sutured to the knee ligaments in anaesthetised animals. Qualitative inspection of locomotion before and after surgery and comparison of gait parameters between left and right sides after surgery suggested that this procedure did not affect the kinematics of locomotion. Animals were anaesthetised using $4.7 \mathrm{mg} / \mathrm{kg}$ xylazine (Paxman; Virbac, Carros, France) and $23.8 \mathrm{mg} / \mathrm{kg}$ ketamine (Imalgene 500; Merial, Duluth, GA, USA), with an additional local injection of lidocaine (Xylocaine 2\%; AstraZeneca, London, United Kingdom). Experimental procedures were in accordance with the French legislation on animal experimentation.

Nine lead markers were attached to the body (Fig. 1). One marker was placed on the back of the head and used to quantify head motion. In our analysis, we ignored trunk deformation due to respiration and regarded the trunk as a solid object defined by three sagittal markers, i.e., an anterior marker at the level of the first thoracic vertebra (VT), a posterior marker on the sacrum (VS), and a ventral marker on the keel (keel). Additionally, lateral markers were attached to the limbs: one at the hip joint $(\mathrm{H})$, one at the knee joint $(\mathrm{K})$, one at the intertarsal joint (IT), one at the metatarsophalangeal joint (MTP) on the distal part of the tarsometatarsus, one distally and laterally on the phalanx of the hallux, and one on the ungual phalanx of toe 3 (claw). Markers were positioned on the right limb only because, when using X-rays, it is difficult to distinguish the right from the left limb. One more marker was attached to the left limb to check for global motion symmetry between the left and right limbs. This allowed us to reject cycles where birds were walking transversely and allowed us to evaluate whether walking was affected by the placement of markers.

Birds were trained to walk along a $2.5 \mathrm{~m}$-long track, with metallic markers placed at $2 \mathrm{~cm}$ intervals. The movements of the quails were voluntary, birds being encouraged to move forward by the presence of another quail at the end of the track. Environmental

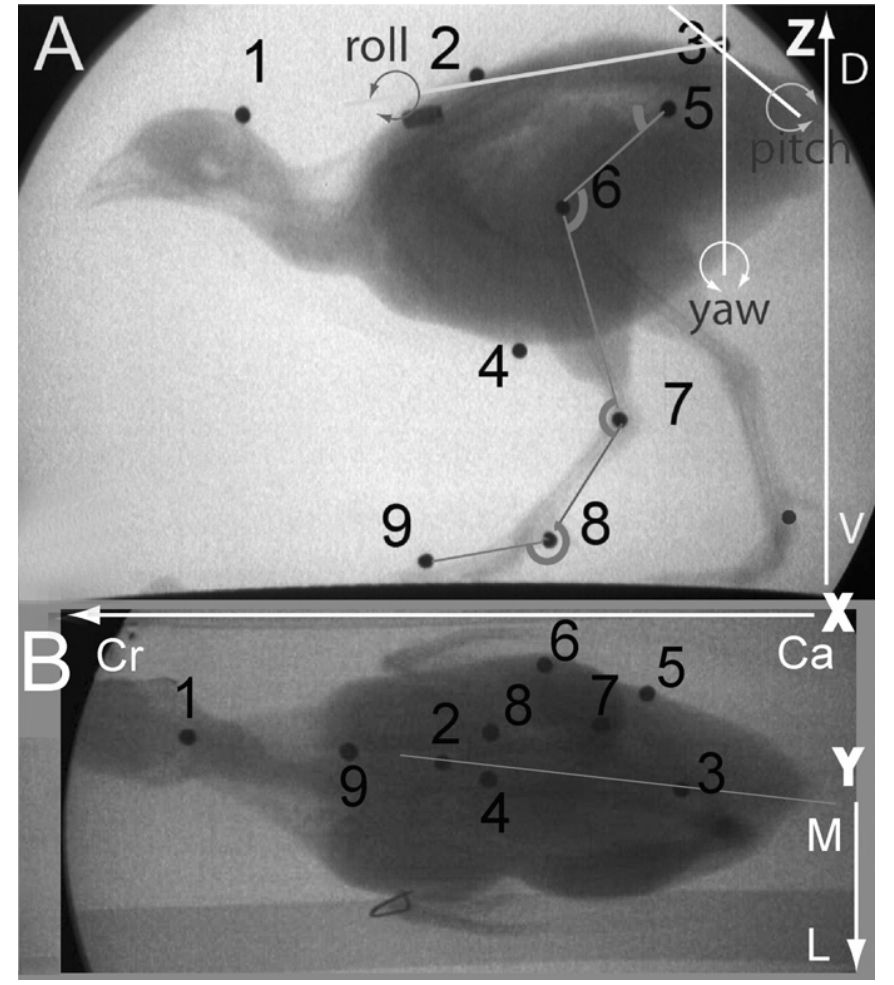

Fig. 1. X-ray frames of a walking quail in (A) lateral and (B) dorsal view. The black points represent the lead markers. $1=$ head; $2=$ vertebral column, thoracic level (VT); $3=$ vertebral column, sacral level (VS); $4=$ keel; $5=$ hip joint; $6=$ knee joint; 7 =intertarsal joint (ankle); $8=$ metatarsophalangeal joint (MTP); $9=$ claw of toe. A lead marker is also visible on the left limb. Measured angles and distances are indicated in grey. The three axes used for analysing the trunk rotation are shown in (A) and comprise the vertical axis (yaw), the medio-lateral axis (pitch) and the longitudinal axis (roll). The three axes intersect at the VS point. The xyz-axes and their orientations are indicated in white. Abbreviations: $\mathrm{Ca}$, caudal; $\mathrm{Cr}$, cranial; D, dorsal; L, lateral; M, medial; V, ventral.

symmetry was found to be important as quails, like mice (Lepicard et al., 2006), are sensitive to their environment and the erectness of their walking posture depends on the amount of space above their heads. Therefore, quails adopt a crooked walk when the environment is asymmetric. A paper tunnel $15 \mathrm{~cm}$ wide and $30 \mathrm{~cm}$ high was placed over the track to ensure that the birds experienced identical environments during lateral and dorso-ventral recordings. The three-dimensional reconstruction of a locomotor cycle based on temporally segregated recordings in lateral and dorso-ventral views requires cycles with a minimal amount of variability associated. Thus, our experimental protocol was designed to minimise variation by assuring a homogeneous visual environment and selection of locomotor cycles at uniform speeds. The videofluoroscopy machine (Philips Diagnost $C$ generator; Philips, Amsterdam, The Netherlands) with a Basler A 504K digital video camera attached (Basler AG, Ahrensburg, Germany) was moved along the track at the same speed as the quail. Ten sequences were recorded at $250 \mathrm{fps}$ for each quail, in lateral and dorso-ventral views, while X-rays were generated at $1.2 \mathrm{~mA}$ and $100 \mathrm{kV}$.

\subsection{Data treatment}

Video recordings were analysed using a custom tracking routine, Loco 2.1, developed in MatLab (by P.A. Libourel, MNHN). Pincushion distortion due to the lens was corrected and the Cartesian coordinates of all landmarks were recorded for each frame. The $x$ - and $z$-coordinates were measured on lateral views, and the $x$ - and $y$ coordinates on dorso-ventral views. 


\section{3. $3 D$ reconstruction from non-synchronised $2 D$ views}

As the lateral view recordings were not synchronised with dorso-ventral ones, a motion warping method was used to match non-synchronised data sets (Witkin and Popović, 1995; Nicolas et al., 2006). This algorithm makes local adjustments to trajectories based on space-time constraints. However, this routine may simultaneously change the shape of the stance phase and the swing phase. Thus, we modified this routine by considering the stance and swing phases separately. This is important as the duration of the swing phase is not correlated with speed, but the duration of the stance phase decreases with increasing speed (Abourachid, 2001). The $3 \mathrm{D}$ reconstruction technique used here allowed us to match the walking cycles recorded in lateral and dorso-ventral views using the $x$-coordinate of the metatarsophalangeal joint marker. The precision of the technique was evaluated by determining the error rates for each leg segment. We found that the error rate between reconstructions varied from $5 \%$ to $22 \%$. Only reconstructions with error rates below $10 \%$ were used for subsequent kinematic analysis (see Hugel et al., 2011 for details). Eighteen reconstructed cycles, based on 40 lateral and 33 dorso-ventral cycles, were selected to extract a mean locomotor cycle as presented in Section 3 (Table 1 and Fig. 2). Because of the time warping used to reconstruct the 3D cycle, this method does not allow to analyse variability in locomotor movements.

We calculated the position of the centre of mass (CoM) in the sagittal plane using the double suspension method (Abourachid, 1993).

\subsection{Gait analysis}

Key instants in the cycle were determined based on a gait analysis (Fig. 3) and used to describe the movements of each part of the body. The locomotor cycle of the right limb was subdivided considering its motion as well as the motion of the contralateral limb.

The stance phase begins when the whole surface of toe 3 (foot) is on the ground. The stance phase lasts until the pre-lift-off phase, during which the MTP is lifted with only the claw remaining in contact with the ground. The swing phase begins with the recovery phase where the claw is positioned behind the MTP. The recovery phase is followed by the positioning phase, during which the claw is positioned in front of the MTP, and lasts until the end of the cycle.

We selected only sequences in which quails walked symmetrically with the cycles of the two limbs strictly alternating. We distinguished four phases, superimposed on those described above, linking the motions of the two limbs. In the right double support phase, both feet are on the ground just after the touch-down of the right foot. During the right single support phase the right foot is on the ground but the left foot is off the ground. During the left double support phase both feet are on the ground just after the touch-down of the left foot. During the left single support phase the left foot is on the ground but the right foot is off the ground.

\subsection{Motion analysis}

We analysed the coordinates of the different landmarks on the body using the sagittal point on the sacrum(VS) as the origin $(0,0,0)$. We used three reference frames:

(1) An external frame of reference allowing us to analyse the motion of the body and the body segments relative to the VS point. The external reference frame is constructed using a vertical plane parallel to the forward direction of the animal (lateral view plane). The $x_{\mathrm{e}}$-axis describes horizontal movements in this plane, with positive

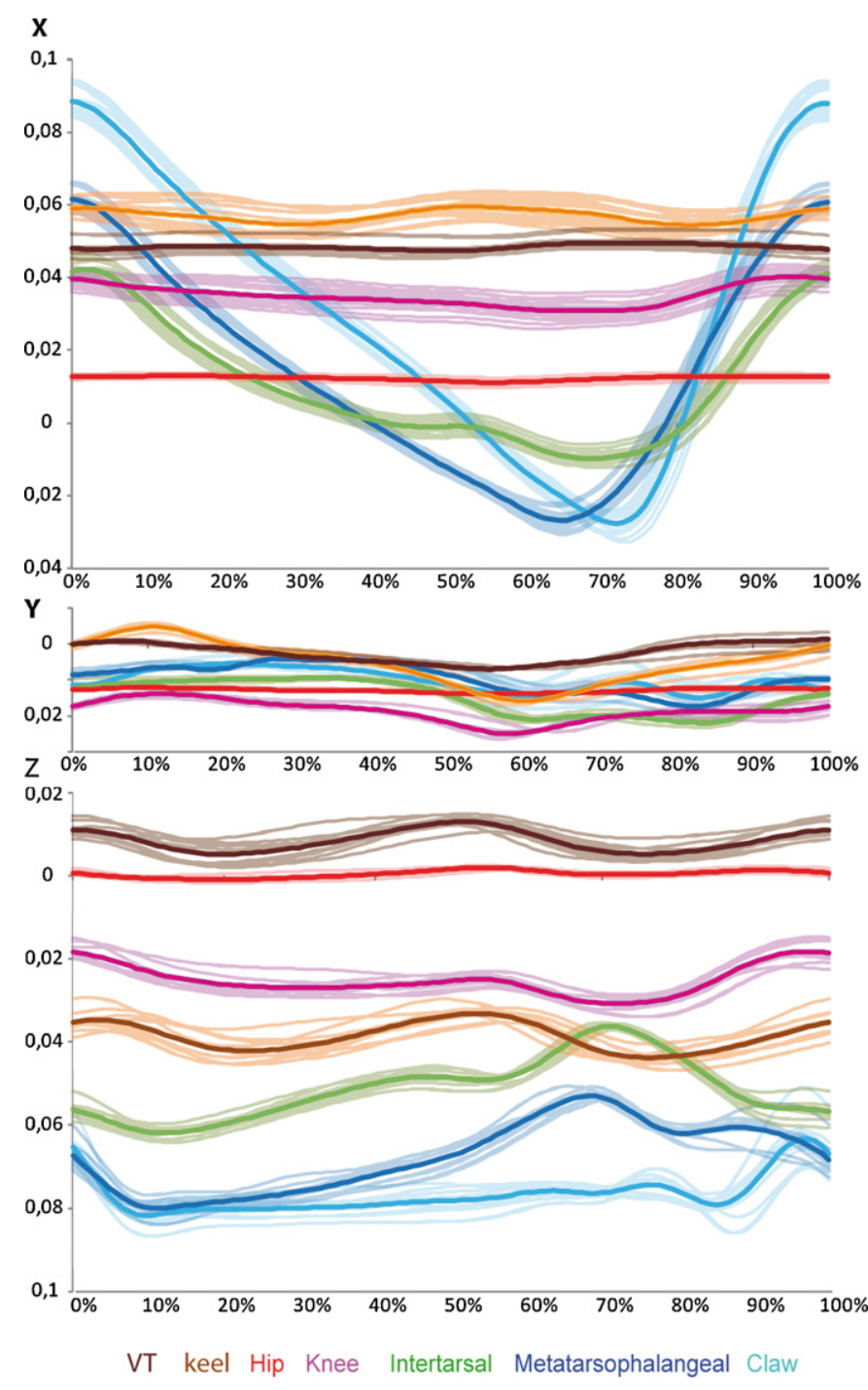

Fig. 2. Representative data used for the construction of the mean locomotion cycle of walking quail relative to total cycle duration. After adjustments that allowed normalising time, the $x$-coordinates of the metatarsophalangeal joint in lateral $(x z)$ and dorso-ventral view $(x y)$ allow the matching of eighteen data sets in $x y z$. Top $=x$ coordinates; middle $=y$-coordinates; bottom $=z$-coordinates .

values corresponding to the forward direction. The $y_{\mathrm{e}}$-axis describes horizontal movements in a plane perpendicular to $x_{\mathrm{e}}$. The $z_{\mathrm{e}}$-axis describes the motion in a vertical plane, perpendicular to $x_{\mathrm{e}}$. By projecting the coordinates of the landmarks into this spatial environment we could visualise the motion of the entire body.

(2) We determined an internal frame of reference $\left(x_{\mathrm{i}}, y_{\mathrm{i}}, z_{\mathrm{i}}\right)$ fixed relative to the sagittal plane of the trunk. It was defined by the keel, the thoracic (VT) and sacral (VS) landmarks. The $x_{\mathrm{i}}$-axis is longitudinal and passes through the VS and VT points. The $z_{\mathrm{i}}$-axis passes through the VS and keel points. The $y_{\mathrm{i}}$-axis is perpendicular to $x_{\mathrm{i}}$ and $z_{\mathrm{i}}$ and corresponds to the transverse axis of the trunk. The projections of the landmark coordinates in this internal frame of reference allowed us to visualise the motion of the limb segments relative to the sagittal plane of the body.

(3) As both the bird and the camera were moving, it was not possible to establish a true environmental reference. However, as during the stance phase the claw does not move relative to the environment, it can be used as a fixed point of reference. Thus, the trajectories of the other landmarks relative to the claw represent movements relative to a true external reference. 
Table 1

Mean values \pm standard deviations of the angles $\left({ }^{\circ}\right.$ ) of the limb segments with the vertical and horizontal plane during 6 key times in a locomotor cycle. The times were chosen to reflect instances when joints share the same X-coordinate (T1-T6). Percentages indicated below the times indicate the proportion of the locomotor cycle. T1, knee and intertarsal joint; T2, metatarsophalangeal and knee; T3, knee and claw; T4, claw and intertarsal; T5, claw and metatarsophalangeal; T6, knee and claw.

\begin{tabular}{|c|c|c|c|c|c|c|}
\hline & $\mathrm{T} 1$ & $\mathrm{~T} 2$ & T3 & $\mathrm{T} 4$ & T5 & T6 \\
\hline Vertical plane & $0 \%$ & $16 \pm 3 \%$ & $31 \pm 3 \%$ & $54 \pm 3 \%$ & $70 \pm 3 \%$ & $86 \pm 2 \%$ \\
\hline Trunk (SV-keel) & $13 \pm 2$ & $7 \pm 3$ & $9 \pm 3$ & $13 \pm 2$ & $7 \pm 2$ & $8 \pm 2$ \\
\hline Femur & $144 \pm 5$ & $134 \pm 6$ & $129 \pm 4$ & $127 \pm 4$ & $122 \pm 3$ & $134 \pm 5$ \\
\hline Tibiotarsus & $90 \pm 2$ & $67 \pm 3$ & $43 \pm 4$ & $35 \pm 3$ & $11 \pm 3$ & $48 \pm 14$ \\
\hline Tarsometatarsus & $150 \pm 5$ & $123 \pm 4$ & $100 \pm 3$ & $43 \pm 6$ & $62 \pm 8$ & $146 \pm 28$ \\
\hline Toe & $182 \pm 4$ & $176 \pm 2$ & $168 \pm 3$ & $134 \pm 6$ & $81 \pm 7$ & $112 \pm 15$ \\
\hline Horizontal plane & $0 \%$ & $17 \pm 3 \%$ & $34 \pm 3 \%$ & $57 \pm 4 \%$ & $73 \pm 4 \%$ & $89 \pm 2 \%$ \\
\hline Trunk (SV-keel) & $167 \pm 4$ & $159 \pm 12$ & $164 \pm 13$ & $175 \pm 3$ & $170 \pm 13$ & $170 \pm 2$ \\
\hline Femur & $165 \pm 8$ & $168 \pm 11$ & $164 \pm 10$ & $153 \pm 9$ & $155 \pm 6$ & $163 \pm 5$ \\
\hline Tibiotarsus & $100 \pm 23$ & $19 \pm 7$ & $15 \pm 5$ & $7 \pm 3$ & $2 \pm 3$ & $-6 \pm 14$ \\
\hline Tarsometatarsus & $161 \pm 25$ & $167 \pm 7$ & $130 \pm 22$ & $23 \pm 17$ & $77 \pm 57$ & $169 \pm 7$ \\
\hline Toe & $169 \pm 21$ & $171 \pm 19$ & $176 \pm 3$ & $170 \pm 23$ & $55 \pm 35$ & $146 \pm 21$ \\
\hline
\end{tabular}

\section{Results}

\subsection{Gait analysis}

The mean duration of the 73 recorded cycles was $0.42 \pm 0.08 \mathrm{~s}$, with a mean duty factor of $0.64 \pm 0.06$ and a mean stride length of $0.11 \pm 0.04 \mathrm{~m}$. In the reconstructed cycle, the quail walked at slow speed, $0.29 \mathrm{~m} / \mathrm{s}$, the cycle duration was $0.4 \mathrm{~s}$, the swing duration was $0.14 \mathrm{~s}$, the duty factor was 0.63 and the stride length was $0.11 \mathrm{~m}$.

During the double support phase, both feet were on the ground just after the touch-down of the right foot $(0-13 \%$ of the cycle; Fig. 3). During the right single support phase, the right foot was on the ground but the left foot was off the ground (13-50\%). During the left double support phase, both feet were on the ground just after the touch-down of the left foot (50-63\%). Finally, during the left single support phase, the left foot was on the ground but the right foot was off the ground (63-100\%).

\subsection{Joint trajectories}

The xyz coordinates of the reconstructed cycle were used to plot joint trajectories (Fig. 4).

\subsubsection{External reference}

Results are presented as projections of the trajectories of the markers in the three perpendicular planes with the VS point being the fixed reference.

Trunk motion is complex and three-dimensional, with both vertical and horizontal movements occurring simultaneously. In the
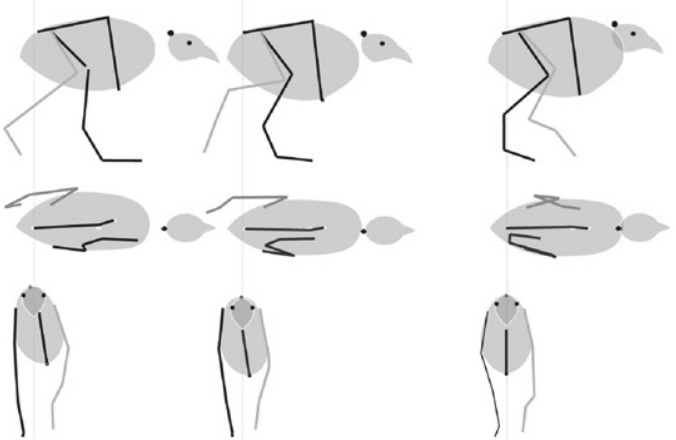

double support

swing phase
STANCE PHASE

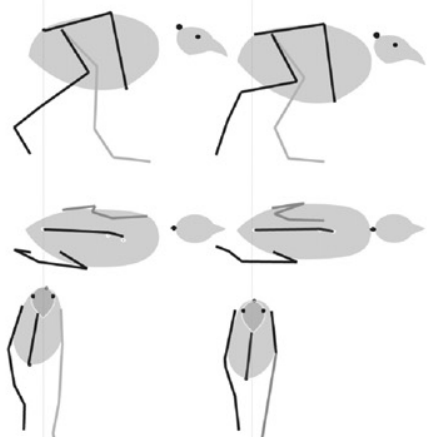

double support
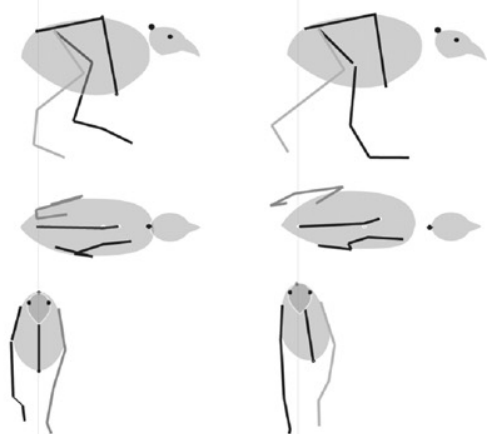

single support

stance phase

\section{SWING PHASE}

whole foot contact

pre-lift off

recovery

positionning

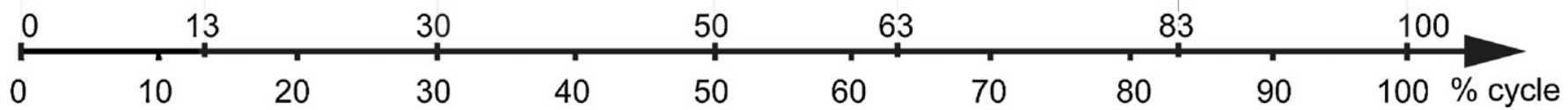

Fig. 3. Quail locomotor cycle and definition of its phases. Walking cycle of the quail in lateral, dorsal and frontal view, represented by seven instants during the cycle of the right foot (dark grey). Time is expressed as percentage of the cycle duration: $0 \%$ : touch-down of the right foot; $13 \%$ : lift-off of the left foot; $30 \%$ : lift-off of the right metatarsophalangeal joint with the claw touching the ground; $50 \%$ : touch-down of the left foot; $63 \%$ : lift-off of the right foot; $83 \%$ : claw of the right foot in front of the metatarsophalangeal joint; $100 \%$ : end of the cycle, with touch-down of the right foot. The phases associated with the movements of the right limb are: stance phase $(0-63)$ and swing phase (63-100); whole-foot contact (0-30), pre-lift-off (30-63), recovery (63-83), positioning (83-100). The phases associated with the movements of the whole body and determined by the positions of both limbs are: double support (0-13); single support right foot (13-50); double support (50-63); single support left foot (63-100). 


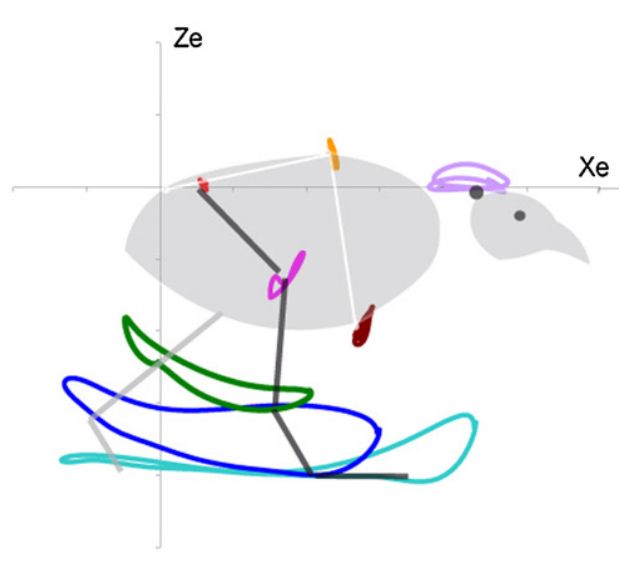

$\mathrm{Zi}$

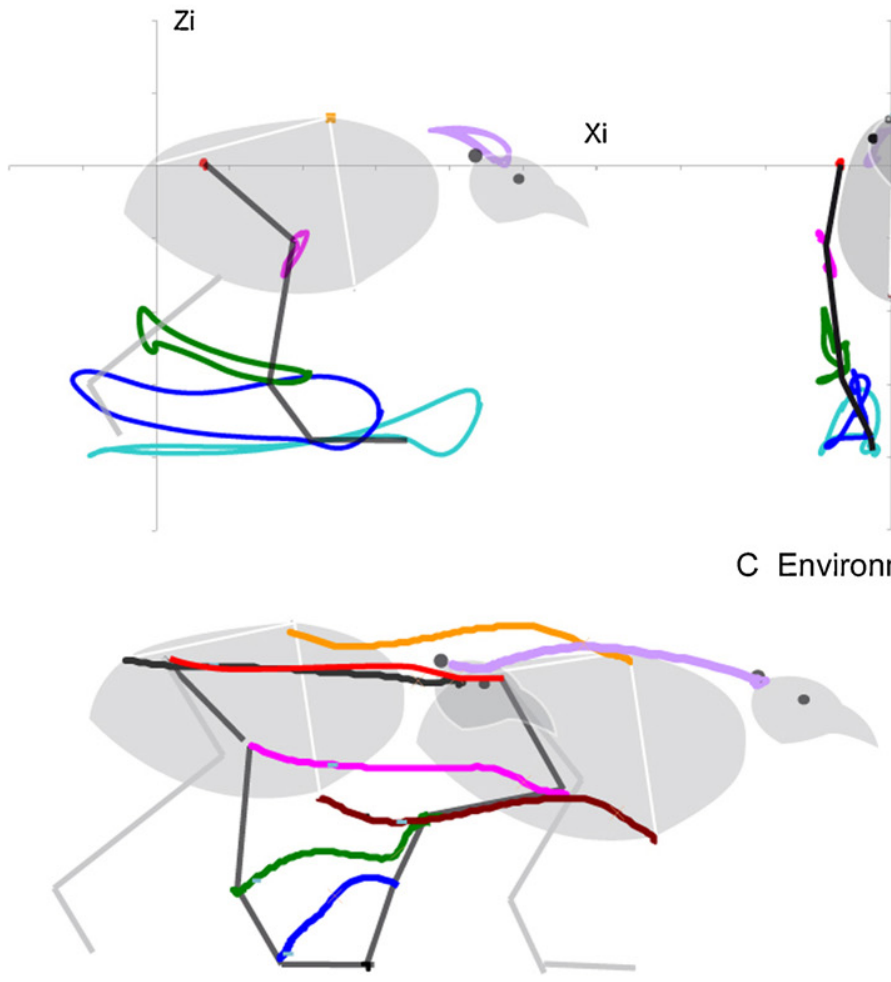

A External reference frame

$\mathrm{Ze}$
Ye

Ye

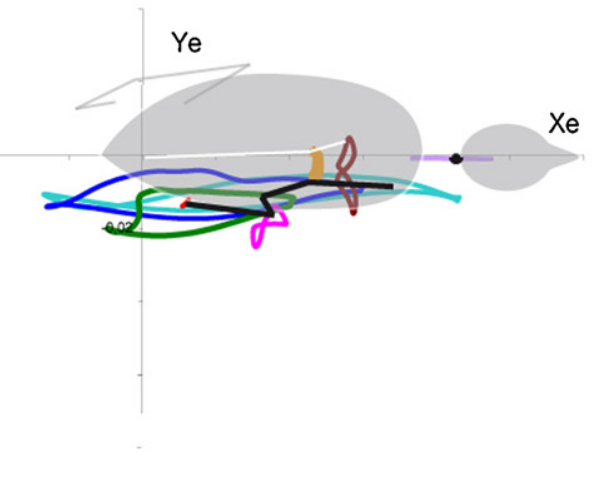

Yi

$\mathrm{Zi}$

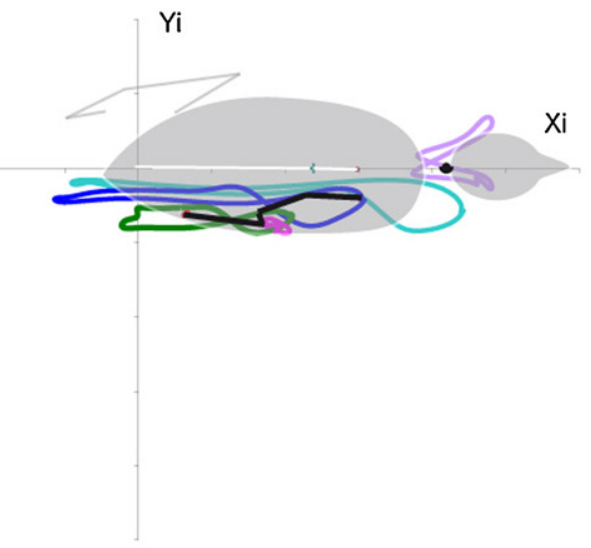

$\mathrm{Xi}$

$x^{x}$

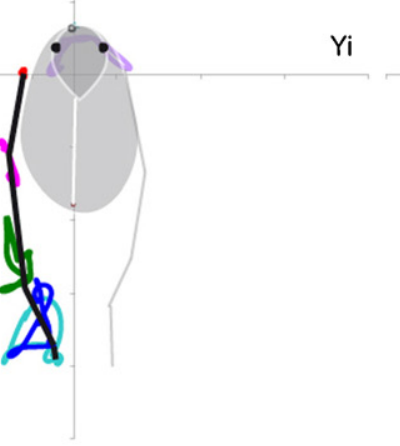

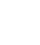


of its path. The ankle and MTP joints have a different trajectory, moving dorsally during the entire stance phase.

In the dorsal plane, the dorsal-most trunk markers (VS, VT and hip) moved medially during stance. The ventral point of the trunk, the keel, moved laterally. The knee was placed almost in the middle of the body and did not exhibit transverse displacements during the single support phase. The ankle and MTP joint moved medially, then laterally during stance.

\subsection{Displacement of the body parts over time}

\subsubsection{Displacement of the trunk}

Trunk rotation was analysed relative to three axes intersecting at the sacrum point. Pitch is the rotation about the latero-medial axis; it moves the cranial part of the trunk up and down. Roll is the rotation about the cranio-caudal axis; it rotates the sagittal plane latero-medially. Yaw is the rotation about the vertical axis; it moves the cranial part of the trunk right and left. The trunk was in a neutral position $\left(0^{\circ}\right)$ with regard to the three directions (a in Fig. $5 \mathrm{~A}$ ) at the middle of the single support phases.

Pitch was double peaked during one locomotor cycle and followed the movements of the two limbs. The trunk was upright from the middle of the single support phase (a) until the middle of the double support phase (b), and then pitched downward from $b$ to a (Fig. 5A). The periods of the medio-lateral motions, the yaw and the roll, were similar to those of the locomotor cycle period. The cranial part of the trunk was positioned laterally, on the side of the swinging foot, at the beginning of stance, and then tipped medially until the middle of the single support phase. Next, the trunk moved laterally towards the side of the stance foot until the touch-down of the other foot at the middle of the locomotor cycle. Then, an inverse motion occurred.

\subsubsection{Displacement of the head}

The head movement is produced by the flexion-extension of the neck. The flexion of the neck was maximal at the middle of the single support phase and its extension was maximal at the middle of the double support phase (Fig. 5B). These maxima coincide with the neutral horizontal position of the trunk pitch (positions a and b in Fig. 5A). During the flexion of the neck, the head is stabile in the environment frame (hold phase) whereas the extension of the neck projects the head forward (thrust phase); therefore the head movements are qualitatively coordinated with the trunk pitch.

\subsubsection{Displacement of the limb joints in the sagittal plane of the trunk (internal reference)}

The anatomical landmarks on the joints were used to follow the displacements of the different limb segments relative to the trunk. Leg joints can be classified into two groups: hip and knee (red and pink, respectively, in Fig. 5) constitute a proximal group corresponding to the thigh and the intertarsal joint; MTP and claw (green and blue, respectively, in Fig. 5) constitute a distal group corresponding to the distal limb. The two groups have different motion patterns (Fig. 5D-F); the proximal group trajectories are nearly parallel, indicating that the femur does not move much.

Along the longitudinal axis $\left(x_{\mathrm{i}}\right)$, the coordinates of the hip and knee change in concert indicating that the femur was stable during the entire locomotor cycle (Fig. 5D). Along the dorso-ventral axis $\left(z_{\mathrm{i}}\right)$, the hip remained stable and the knee slowly moved downward during the stance phase and upward during the swing phase (Fig. 5E). Along the medio-lateral axis $\left(y_{\mathrm{i}}\right)$, the knee moved slightly medially during the double support phase, remained stable during the single support phase and moved medially at the end of stance during the double support phase (Fig. 5F). The knee moved laterally during the swing phase. The very small displacements of the knee marker in the internal reference frame during stance indicate that the thigh moved with the trunk when the body was supported by the limb.

Distal segments and joints had larger displacements. Along the longitudinal axis $\left(x_{\mathrm{i}}\right)$, they moved caudally relative to the trunk during the stance phase and cranially during the swing phase (Fig. 5D). Along the dorso-ventral axis $\left(z_{\mathrm{i}}\right)$, they moved upward during the stance and downward during the swing phase (Fig. 5E). The intertarsal joint displacement accelerated during the double support phase at the end of the stance. Along the medio-lateral axis $\left(y_{\mathrm{i}}\right)$, the distal joints engaged in a medial movement at the middle of the first double support phase such that at the beginning of the single support phase the distal limb was in the sagittal plane (Fig. 5F). As the foot was fixed on the ground during the stance, the apparent motion of the distal limb corresponds to a translation of the trunk. The joints remained stable until the end of the single support phase, when a lateral motion began that lasted until the onset of the swing phase. During the swing phase, the joints remained stable until the end of recovery when a medial and then lateral motion moved them laterally for the touch-down.

The longitudinal displacement of the distal parts of the limb contributed to the forward displacement of the body. The longaxis rotation of the femur during the double support phase moved the lower limb medially and allowed placement of the body above the foot during the single support phase. The displacement patterns of the proximal and distal segments thus were different. This difference is not obvious when examining the angular variation at the limb joints in an external reference frame (Fig. 5C). The associated movements of the femur (moving with the trunk) and of the tibiotarsus (moving with the distal limb) flexed the knee joint during the stance. However, the motions of the intertarsal and metatarsophalangeal joints were roughly parallel.

\section{Discussion}

The present study involves a novel method, based on planar, temporally segregated X-ray recordings, allowing to reconstruct 3D movements of the body and limbs during locomotion. In order to obtain the three coordinates, a motion-warping method was used to match up non-synchronised data sets. In doing so, variability during locomotion due to, for example, variation in speed, is minimised.

We decided to focus our analysis on walking, a terrestrial locomotor behaviour common to most birds. During terrestrial locomotion, all parts of the bird's body move except for the wings and the tail (Gatesy and Dial, 1996). To evaluate the participation of each part in the animal's motion, we measured the relative movements of the different body parts.

The pattern described for the angular flexion in our study (Fig. 5C) is similar to that described for the pigeon (Cracraft, 1971), the silver gull (Dagg, 1977), the chicken (Jacobson and Hollyday, 1982), the quail (Reilly, 2000), the turkey (Abourachid, 1990), ratites (Abourachid and Renous, 2000) and the magpie (Verstappen and Aerts, 2000). Moreover, the 3D movements of the proximal part of the limb are similar to those described for guinea fowl (Gatesy, 1999a) and ostriches (Jindrich et al., 2007; Rubenson et al., 2007). Thus, the 2D kinematics of the bird limb during walking appears consistent among different bird species. The pitch, roll and yaw of the trunk have been described for other birds and follow the same patterns as described here for the quail. However, movements of the trunk were found to be smaller in ostriches (yaw and roll $<4^{\circ}$, pitch $<6^{\circ}$; Jindrich et al., 2007; Rubenson et al., 2007) and slightly larger in guinea fowl (pitch $<10^{\circ}$, yaw $<10^{\circ}$; Gatesy, 1999a). As the pattern is similar for most species 


\section{Body motion, external reference frame}
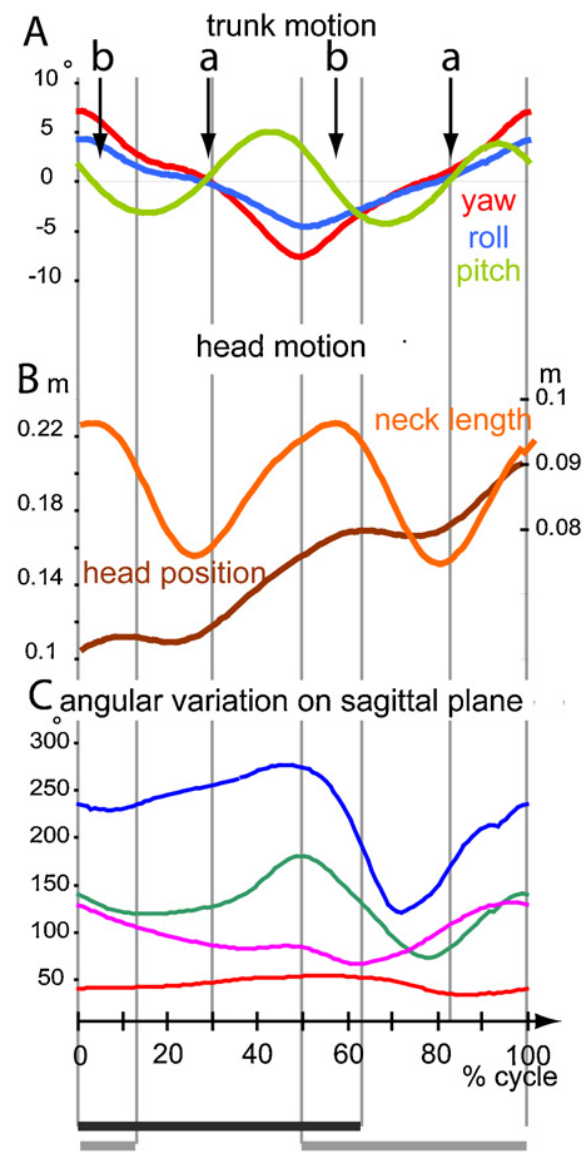

Limb motion, internal reference frame

D Xi longitudinal

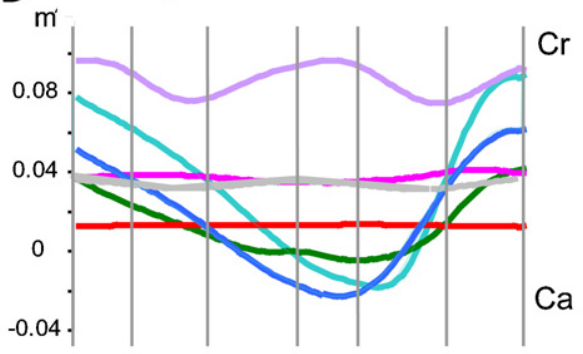

E Zi dorso-lateral
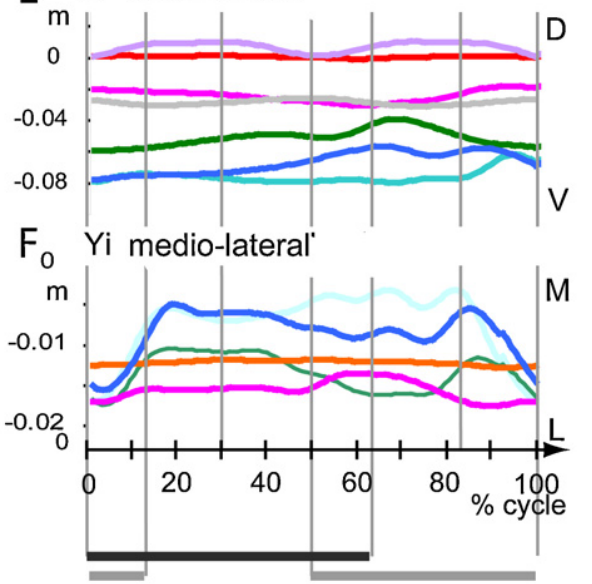

\section{Head CoM Hip Knee Intertarsal Metatarsophalangeal Claw}

Fig. 5. Coordination of the motion of all parts of the body during one locomotor cycle. The positions of the parts and landmarks are plotted versus time (\% of cycle duration). Vertical grey lines demarcate the periods of the cycle. On the bottom, the dark line represents the stance phase of the right limb, the light line the stance phase of the left limb. The zero position represents the position of the VS point. Left column: body motion in the external reference frame. (A) Trunk motion: angular variation of the sagittal plane of the trunk (VS, VT, keel) about the axis. Zero is defined as the mean for the entire cycle. The arrows indicate the mean position of the pitch. (B) Head motion. The left axis provides a reference frame for the forward position of the head, the right axis one for the length of the neck, between the VT point and the head point. (C) Angular variations on the sagittal plane. Angles between the segments of the limb are defined in Fig. 1. Right column: limb motion in the internal reference frame with the sagittal plane of the trunk (VS, VT, keel) fixed and 0 being the VS point. (D) Longitudinal coordinates of the points $\left(x_{i}\right.$-axis). Positive values are cranial to the VS point, negative values are caudal. (E) Vertical coordinates of the points ( $z_{\mathrm{i}}$-axis). Positive values are dorsal to the VS point, negative values are ventral. (F) Lateral coordinates of the points $\left(y_{\mathrm{i}}\right.$-axis). Positive values are lateral to the VS point, negative values are medial.

studied so far, our observations for the quail appear to fit the general pattern.

\subsection{Head bobbing, locomotion, and trunk kinematics}

Head bobbing is a stabilising reflex observed only in certain birds, and is considered to be of visual origin (Troje and Frost, 2000). Nevertheless, it has been suggested that this reflex may also be modulated by behavioural (Maurice et al., 2006) and biomechanical factors (Fujita, 2002, 2003). It has already been reported that head thrust begins when the foot in swing is positioned beneath the CoM in the pigeon (Fujita, 2003, 2006), but no strict synchronisation was found for the onset of the hold phase. Hancock (2010) reported that in tinamous, the timing of head bobbing is independent of the timing of hind limb movement. Indeed, pitching of the trunk and head bobbing movements were not synchronised, and were primarily affected by locomotor dynamics, and secondarily by the hold phase of head bobbing.

We therefore suggest that the trunk is a good candidate for providing the trigger for head stabilisation during the hold phase. We found that head hold began when the trunk passed its middle position during the downward pitching motion, and that thrust began when the trunk passed its middle position during the upward pitching motion. This middle position of the trunk is also synchronised with the positioning of the foot in swing under the CoM, as noted by Fujita $(2002,2003)$. Thus, the coordination of head motion in walking birds that display head bobbing may result from the coordination of head motion with trunk motion. The synchronisation of the head with the leg movements could then potentially be a side effect of the synchronisation of the legs with the trunk. Interestingly, Hancock (2010) reports that the COM mechanics are not demonstrably affected by head bobbing. The mechanisms underlying this complex synchronisation remain unknown and may involve a central pattern generator localised in the brain or in the spinal cord. The lumbo-sacral apparatus of birds is an organ of equilibrium which is located in the trunk and involved in the control of balance during walking (Necker, 2002, 2006). As such, it could detect the neutral position of the trunk important in the trunk-head coordination and thus be involved in driving or triggering the synchronisation between trunk and head.

\subsection{Trunk-limb coordination}

In limbed locomotion, the feet are immobile during stance and mobile during swing. The role of the limbs is to transform the discontinuous longitudinal foot motion into a continuous motion 


\section{DORSAL}
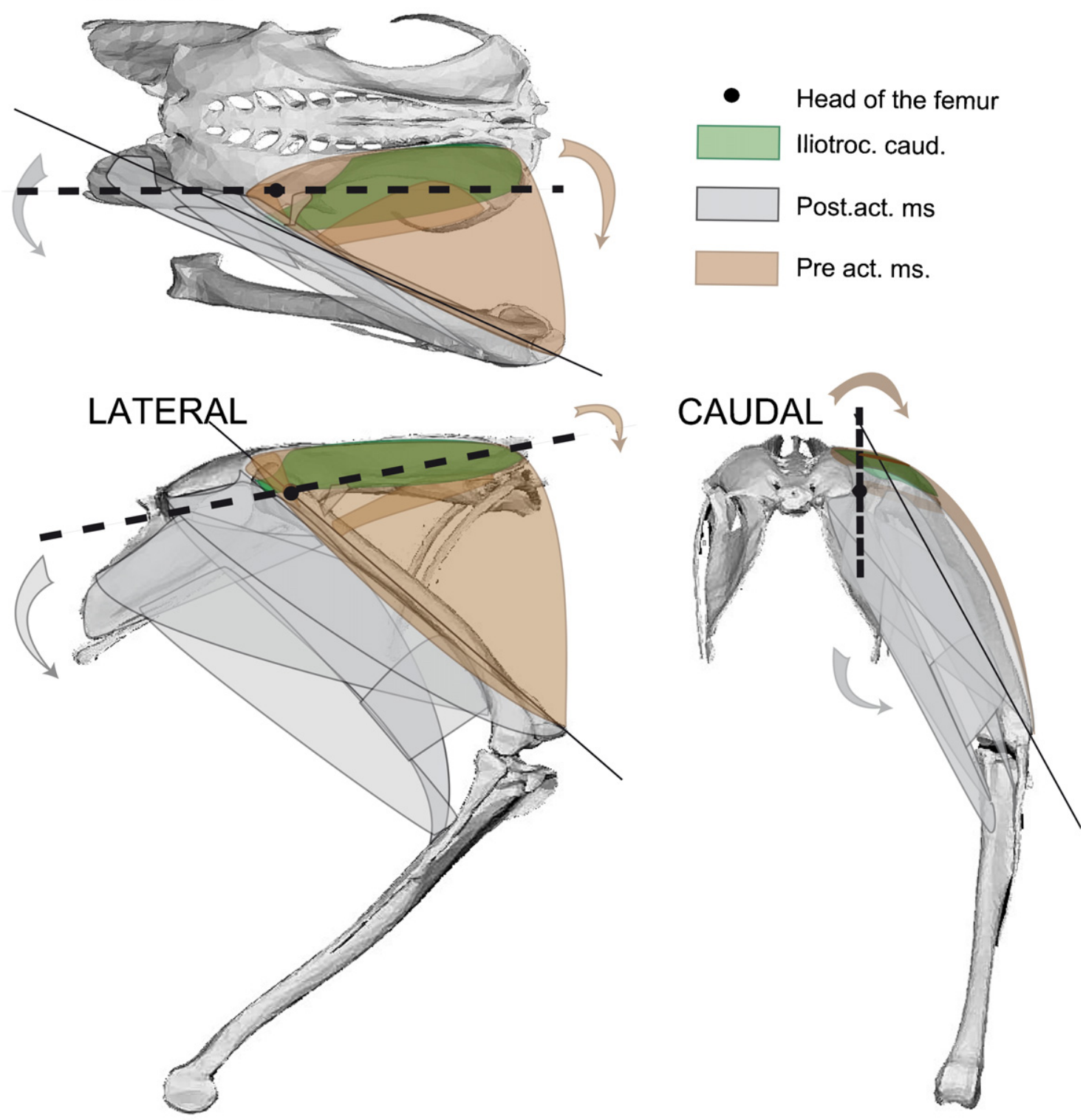

Fig. 6. Thigh musculature and its possible effects on the trunk motion of the quail in dorsal, lateral and caudal views. Dashed line = axis on the pelvis crossing the head of the femur; fine line = long axis of the femur. Arrows = hypothesised effects of muscle contraction on the trunk if the femur is fixed. Abbreviations: Iiotroc.caud.: m. iliotrochantericus caudalis; Post-act.ms: post-acetabular muscles; Pre-act.ms: pre-acetabular muscles.

of the trunk. Our results show that the trunk and knee motions are rather similar during terrestrial locomotion, whereas the distal limb joints' trajectories follow a different pattern. In the forward direction, the transformation from discontinuous to continuous forward movement thus appears to occur at the level of the distal limb. In the transverse direction, the knee follows a nearly rectilinear parasagittal trajectory (Fig. 3). Interestingly, in birds the centre of mass is located at the level of the knee (Abourachid, 1993; Clark and Alexander, 1975) and thus, the three-dimensional movements of the trunk may help maintain the centre of mass on a rectilinear trajectory, minimising its medio-lateral motion and potentially limiting the energetic cost of travel.

In quails, the trunk (including the wings) represents about 70\% of the mass of the bird. Even if the range of motion is small, muscular power is still needed to move the trunk. The femur showed relatively small displacements relative to the trunk during the stance phase, and consequently it can be deduced that the powerful thigh muscles that move the leg in a parasagittal plane also move the trunk. The activation pattern of the muscles recorded during walking (Johnston and Bekoff, 1996; Gatesy, 1999b) shows two main muscle groups with distinct activities: the post-acetabular muscles which are hip extensors, and the pre-acetabular muscles acting as hip flexors. The hip extensors are activated from late swing to late stance whereas the hip flexors are activated from late stance to late swing. The beginning of the activation of each group of muscles corresponds to the beginning of the double support phase, and is thus in phase with the yaw and roll of the trunk. Moreover, anatomical observations show that the spatial organisation of the pelvic musculature is coherent with functioning as a trunk motor (Fig. 6). In fact, the hip flexor muscles can either move the femur up, or move the trunk down or laterally. Hip extensor muscles can either move the femur down, or move the trunk up and/or medially. If we suppose that the femur is the fixed part of the system, the femur could be regarded as the origin and the pelvis as the insertion of 
the monoarticular muscles that cross the hip. Consequently, if the femur is stabilised externally, the activation of these muscles would move the trunk rather than moving the femur. The pelvis is narrower cranial to the acetabulum and wider caudally. This complex shape places the origin of the pre-acetabular muscles medial to the femoral head, whereas most post-acetabular origins are lateral to the femoral head. This could increase the moment arms of these muscles around the hip joint. The proximal muscle, the m. iliotrochantericus caudalis, which can act as a rotator of the femur (Gatesy, 1999b), may also have a function in driving the trunk yaw. The neck of the femur places the femoral head medial to the long axis of the bone, and the shape of the antitrochanter is thought to play a role in the complex three-dimensional motion of trunk and limb (Hertel and Campbell, 2007).

\section{Conclusion}

The study of the whole-body kinematics of the quail showed that two sub-systems are used during walking: the two joints of the distal limbs (metatarsophalangeal joint and intertarsal joint) transform the alternating 3D motion of the feet into a forward motion at the level of the knee. The hip joint, located caudally, allows the positioning of the femur and of the trunk to adjust the position of the path of the COM in the forward motion, independent of the foot which is on the ground. Both subsystems must interact, and the thigh musculature that crosses the hip joint may help to adjust the 3D motions of the trunk. The ability of the hip joint muscles to modulate the COM trajectory may also be involved in the vaulting or bouncing COM mechanics observed at intermediate speeds (Hancock et al., 2007), and in the smooth walk-run transition in birds (Gatesy and Biewener, 1991). The trunk may also be involved in the coordination of the head-bobbing visual reflex by synchronising the motion of the head with the pitch of the trunk, crucial to the biomechanics of walking in birds.

\section{Acknowledgements}

We thank A. Herrel for his suggestions and for improvement of the English, and two anonymous referees for helpful and constructive remarks. We thank C. Leterrier, INRA, for providing quails and suggestions for knee marker implantation. Thanks to E. Pellé for looking after the quails and to $\mathrm{H}$. Clamouze for technical assistance. This study was supported by ROBEA, ANR Locomo and the ATM formes.

\section{References}

Abourachid, A., 1990. Etude morpho-fonctionnelle de l'appareil locomoteur de deux souches de dindons domestiques. Recherche d'une explication fonctionnelle aux boiteries des dindons ultra-lourds. Ph.D. Thesis, Université de Rennes 1, Rennes.

Abourachid, A., 1993. Standing mechanics in birds, functional explanation to lameness problems in giant turkeys. Br. Poult. Sci. 34, 887-898.

Abourachid, A., 2001. Comparison of kinematic parameters of terrestrial locomotion in cursorial (ratites), swimming (ducks) and striding birds (quail and guinea fowl). J. Comp. Physiol. A 131, 113-119.
Abourachid, A., Renous, S., 2000. Bipedal locomotion in ratites (Paleognatiform): examples of cursorial birds. Ibis 142, 538-549.

Clark, J., Alexander, R.M., 1975. Mechanics of running by quail (Coturnix coturnix). J. Zool. Lond. 176, 87-113.

Cracraft, J., 1971. The functional morphology of the hind limb of the domestic pigeon, Columba livia. Bull. Am. Mus. Nat. Hist. 144, 175-265.

Dagg, A., 1977. The walk of the silver gull (Larus novaehollandidae) and other birds. J. Zool. Lond. 19, 529-540.

Frost, B., 1978. The optokinetic basis of head-bobbing in pigeon. J. Exp. Biol. 74, 187-195.

Fujita, M., 2002. Head bobbing and the movement of the centre of gravity in walking pigeons (Columba livia). J. Zool. Lond. 257, 373-379.

Fujita, M., 2003. Head bobbing and the movement of the body movement of little egrets (Egretta garzetta) during walking. J. Comp. Physiol. A 189, 53-58.

Fujita, M., 2006. Head-bobbing and non-bobbing walking of black-headed gulls (Larus ridibundus). J. Comp. Physiol. A 192, 481-488.

Gatesy, S.M., 1999a. Guineafowl hind limb function. I. Cineradiographic analysis and speed effects. J. Morphol. 240, 115-125.

Gatesy, S.M., 1999b. Guineafowl hind limb function. II. Electromyographic analysis and motor pattern evolution. J. Morphol. 240, 127-142.

Gatesy, S.M., Biewener, A.A., 1991. Bipedal locomotion: effects of speed, size and limb posture in birds and humans. J. Zool. Lond. 224, 127-147.

Gatesy, S.M., Dial, K.P., 1996. Locomotor modules and the evolution of avian flight. Evolution 50, 331-340.

Hancock, J.A., 2010. The mechanics of terrestrial locomotion and the function and evolutionary history of head-bobbing in birds. Ph.D. Thesis, Ohio University.

Hancock, J.A., Stevens, N., Biknevicius, A.R., 2007. Whole-body mechanics and kinematics of terrestrial locomotion in the elegant-crested tinamou Eudromia elegans. Ibis 149, 605-614.

Hertel, F., Campbell Jr., K.E., 2007. The antitrochanter of birds: form and function in balance. Auk 124, 789-805.

Hugel, V., Hackert, R., Abourachid, A., 2011. Kinematic modeling of bird locomotion from experimental data. IEEE Trans. Rob. 27, 185-200.

Jacobson, R.D., Hollyday, M., 1982. A behavioural and electromyographic study of walking in the chick. J. Neurophysiol. 48, 238-256.

Jindrich, D.L., Smith, N.C., Jespers, K., Wilson, A.M., 2007. Mechanics of cutting maneuvers by ostriches (Struthio camelus). J. Exp. Biol. 210, 1378-1390.

Johnston, R., Bekoff, A., 1996. Pattern of muscle activity during different behaviours in chicks: implications for neural control. J. Comp. Physiol. A 179, 169-184.

Lepicard, E.M., Venault, P., Abourachid, A., Pelle, E., Chapouthier, G., Gasc, J.-P., 2006 Spatio-temporal analysis of locomotion in BALB/cByJ and C57BL/6J mice in different environmental conditions. Behav. Brain Res. 167, 365-372.

Maurice, M., Gioanni, H., Abourachid, A., 2006. Influence of the behavioural context on the optocollic reflex (OCR) in pigeons (Columba livia). J. Exp. Biol. 209, 292-301.

McGowan, P.J.K., 1994. Family Phasianidae. In: Del Hoyot, J., Elliot, A., Sargatal, J. (Eds.), Handbook of the Birds of the World, vol. 2. Lynx Edicions, Barcelona, pp. 434-552.

Necker, R., 2002. Mechanosensitivity of spinal accessory lobe neurons in the pigeon. Neurosci. Lett. 320, 53-56.

Necker, R., 2006. Specializations in the lumbosacral vertebral canal and spinal cord of birds: evidence of a function as a sense organ which is involved in the control of walking. J. Comp. Physiol. A 192, 439-448.

Necker, R., 2007. Head-bobbing of walking birds-a review. J. Comp. Physiol. A. 193, 1177-1183.

Nicolas, G., Multon, F., Berillon, G., Marchal, F., 2006. Plausible locomotion for bipedal creatures using motion warping and inverse kinematics. LNCS 4035 586-593.

Reilly, S.M., 2000. Locomotion in the quail (Coturnix japonica): the kinematics of walking and increasing speed. J. Morphol. 243, 173-185.

Rubenson, J., Lloyd, D.G., Besier, T.F., Heliams, D.B., Fournier, P.A., 2007. Running in ostriches (Struthio camelus): three-dimensional joint axes alignment and joint kinematics. J. Exp. Biol. 210, 2548-2562.

Troje, N., Frost, B., 2000. Head-bobbing in pigeons: how stable is the hold phase? J. Exp. Biol. 203, 935-940.

Verstappen, M., Aerts, P., 2000. Terrestrial locomotion in the black-billed magpie, Pica pica. I. Spatio-temporal gait characteristics. Motor Control 4, 150-164.

Witkin, A., Popović, Z., 1995. Motion warping. In: Proceedings of SIGGRAPH 95, ACM SIGGRAPH, pp. 105-108 